cases under review, and of the effects present as a result of wearing glasses at the commencement of treatment by orthopsis. The findings are that 3 only were straight with glasses, 25 showed reduction, and 44 showed no change, and the conclusion is reached that the lower degrees of squint are most likely to become straight with glasses, but then an ${ }_{i}$ essential condition of this eventuality is the pre-existence of S.P.F. and a capacity for developing G.S.V.: that not even all such became straight, but that with the addition or orthoptic treatment they are very likely to do so.

6. The possible causation of strabismus in the light of these findings is discussed, and the conclusion is reached that the absence of or failure of S.V. is the main aetiological factor in the production of concomitant strabismus.

7. Some objections to this theory are discussed, but are not thought to invalidate it.

My best thanks are due to Miss M: Levinge, Orthoptist at the West Bromwich and District Hospital, without whose willing and enthusiastic help this investigation would have been impossible.

\title{
Abbreviations
}

S.V. = Stereoscopic Vision.

G.S.V. = Good Stereoscopic'Vision.

F.S.V. = Fair Stereoscopic Vision.

P.S.V. = Poor Stereoscopic Vision.

S.P. = Simultaneous Perception:

S.P.F. = Simultaneous Perception and Fusion.

W.F. $=$ Weak Fusion.

A.R.C. = Abnormal Retinal Correspondence.

\section{PENETRATION OF PENICILLIN INTO THE EYE*}

\section{BY}

R. E. Wright, Temp.-Major, I.M.S.

and

C. H. Stuart-HarRis, Lieut.-Col., R.A.M.C.

A FEW observations have been made on the penetration of penicillin into the eye after administration in various ways. Aqueous humour was collected by one of us (R.E.W.) and examined in the laboratory (C.H.S.-H.) by techniques designed to reveal the presence of substances inhibitory to bacteria. Table I shows clinical details, mode of administration of penicillin and interval bétween therapy and collection of aqueous humour.

\footnotetext{
- Received for publication, July 5, 1945.
} 


\section{Clinical technique}

The continuous irrigation or drip into the conjunctival sac was carried out as suggested by one of us (R.E.W., 1944).

Before performing paracentesis of the anterior chamber four instillations of 4 per cent. cocaine hydrochloride were given. The usual precautions to attain sterility of apparatus and avoid intro-, ducing intra-ocular infection were taken. The conjunctival sac was irrigated with sterile normal saline for 2 minutes prior to penetrating the cornea. The syringe used for withdrawing aqueous humour was an all-glass tuberculin syringe, the needle of fine calibre with short bevelled point. Since this type of needle does not penetrate the cornea without undesirable pressure trauma, it was introduced along the track of a preliminary puncture with a Bowman's needle. The syringe containing aqueous fluid was passed immediately to the laboratory. Permission was obtained for paracentesis when this was not indicated as a therapeutic.procedure. Penicillin administration by corneal bath was not investigated as suitable contact apparatus was not available. Captain H. Duncan; R.C.A.M.C., kindly gave a verbal description of the technique of penicillin iontophoresis as used by $\mathrm{Dr}$. MacMillan, Professor of Ophthalmology, Royal Victoria Hospital, Montreal, in the Physiotherapy Department an improvised technique was based. We have to thank him also for giving us access to the two battle casualties referred to in the series of cases which were under his care at No. 4 Canadian General Hospital. The galvanic apparatus used for intranasal iontophoresis at the Military Hospital was employed. The current tension was 40 volts. The indifferent electrode (zinc sheet suitably padded.with moist absorbent and insulated from the table) was placed behind the patient's neck or shoulders and connected with the positive pole of the battery. Precautions for insulating the apparatus were taken. Since an active electrode especially constructed for the purpose was not available an improvised electrode was tentatively employed. We understand that an electrode similar to that in the Royal Victoria Hospital was made subsequently by Messrs. John Weiss for Lt.-Col. Elkington, Consulting Ophthalmic Surgeon, R.C.A.M.C. In Case 10 our active electrode consisted of a rubber vaccine-bottle cap filled with absorbent cotton which projected from the open end. This was saturąted with penicillin solution (sodium salt) $1000 \mathrm{u} / \mathrm{c} . \mathrm{c}$. dissolved in normal saline. A sharp needle terminal connected with the negative pole perforated the convexity of the cap and made contact with the absorbent cotton. The projecting saturated cotton covered the whole corneal surface. Fresh solution was run in to the projecting cotton from time to time during the passage of the 
current. No speculum was used. A current of $2 \mathrm{~mm}$. amps. was let in gradually and passed for 5 minutes. This crude electrode although unsatisfactory seemed to answer the purpose without any undesirable complications. Cocaine hydrochloride 4 per cent. drops were used for surface anaesthesia.

In case 12 a metal speculum was used and a pack of absorbent cotton saturated with the penicillin solution was built up on the cornea. The apex of the cotton was contacted with the negative needle terminal. The penicillin solution saturating the cotton was replenished with a pipette during the passage of the current. This was not satisfactory and a corneal nebula was produced. It was obvious that a carefully constructed -active electrode was essential for iontophoresis therapy, but our improvised technique served to establish the fact of the penetration of penicillin ions to the aqueous humour through the undamaged or partially damaged cornea. In case 11 (b) a similar procédure was adopted without damage to the cornea.

\section{Bacteriological technique}

The first six specimens were examined for penicillin by the technique of inhibition of colony formation by tine Oxford " $H$ " strain of staphylococcus aureus in slide-cells (Bigger, et al, 1944). The aqueous humour or serum was diluted in volumes of a normal human serum, 0.25 c.c. of each dilution were inoculated with a standard loopful of a 1/1000 dilution of an 18-hour broth culture of the staphylococcus, and with each dilution a slide-cell was filled. The cells were incubated for 20 hours. Counts were then made of the number of visible colonies and the results were compared with the colony counts in normal serum and in serum in which dilutions of a "standard" penicillin solution had been made. This "standard" was prepared by dilution of therapeutic penicillin and was assayed by the Heatley plate technique (Heatley, 1944). Because of the need to dilute the aqueous humour at least once with serum in order to support the growth of staphylococcal colonies, the highest concentration of aqueous humour examined in this way was a $1: 2$ dilution.

The remaining specimens were examined both by the above technique and by the technique of Fleming (1945). In the latter case, dilutions of aqueous humour in saline, to which 50 per cent. defibrinated human group " $O$ " blood, infected with an 18-hour culture of a haemolytic streptococcus was added, were incubated in capillary tubes in the horizontal position. After 18 hours incubation, the tubes were stood in the vertical position and the degree of haemolysis of the red cells estimated as an indication of bacterial growth. Dilutions of a "standard" penicillin solution 
and normal serum were used as controls. Because of the nutrient property of the added blood, neat aqueous humour could be examined. The method was slightly more sensitive than the slidecell technique but the estimated content of penicillin in terms of the "standard" was the same in the aqueous humours-or sera examined by both methods.

\section{Results}

Fifteen specimens of aqueous humour and three of serum were examined from eleven patients. Table II sets out the results of the various estimations on the various specimens of aqueous humour. Positive bacteriostasis (column 4) was defined by the absence of colony formation at some dilution or other in the slidecell test, or by complete absence of haemolysis in the streptococcal test. The figures in column 5 give the highest dilution of fluid with entire absence of colonies in the appropriate slide-cell except in the case of the specimens marked with an asterisk. These two fluids had no bacteriostatic effect when diluted and examined by slide-cell test but undiluted fluid in each case completely prevented haemolysis in the streptococcal test. The estimated penicillin content (column 6) was calculated by comparison of the results with the penicillin "standard" solution examined at the same time and by the same technique.

The table shows that fluids from cases $1,7,10,11$ and 12 had detectable inhibitory action. The estimated concentration of penicillin was $1 / 16$ Oxford unit per c.c., $\frac{1}{8}$ unit and $\frac{1}{4}$-unit respectively in three instances, one unit in three instances and two units in the seventh specimen. The results showed that penicillin eitker does. not pass into the aqueous humour from the blood or reaches a much lower concentration than that present in the serum. The level of penicillin in serum collected at the same time as the collection of aqueous humour was estimated in cases 8 and 11.. The serum from case 8 had an estimated 4 units of penicillin per c.c., that from case 11 collected 30 minutes after the intra-muscular penicillin had 4 units per c.c., and 60 minutes after the injection of penicillin there was still 2 units per c.c. in the serum. The aqueous humour from case 8 was devoid of penicillin, that from case 11 (a), 30 minutes after the penicillin showed inhibition in neat fluid (1/16 unit of penicillin) and at 60 minutes no inhibition was detected in the secondary 'aqueous humour at $1: 2$ but the fluid was not examined undiluted. On another occasion (11(b)), secondary aqueous collected 80 minutes after intra-muscular penicillin gave complete bacteriostasis at a dilution of $1: 2$ büt higher dilutions were not tested. The fluid from all three eyes treated by ionisation, showed strongly inhibitory action (1 unit per c.c.), but 
432 R. E. WRIGHT and C. H. STUART-HARRIS

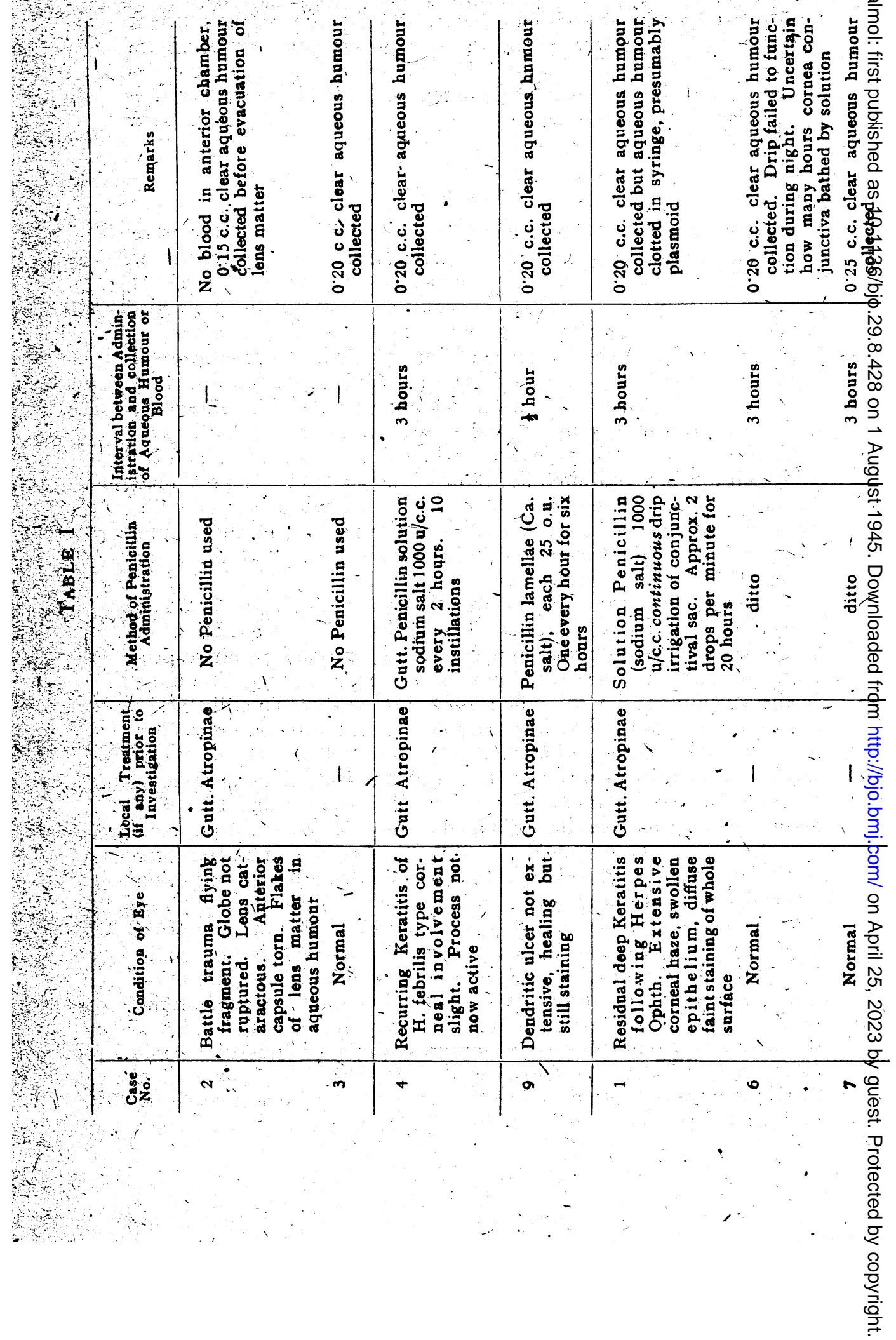


Penetration of Penicillin into The Eye

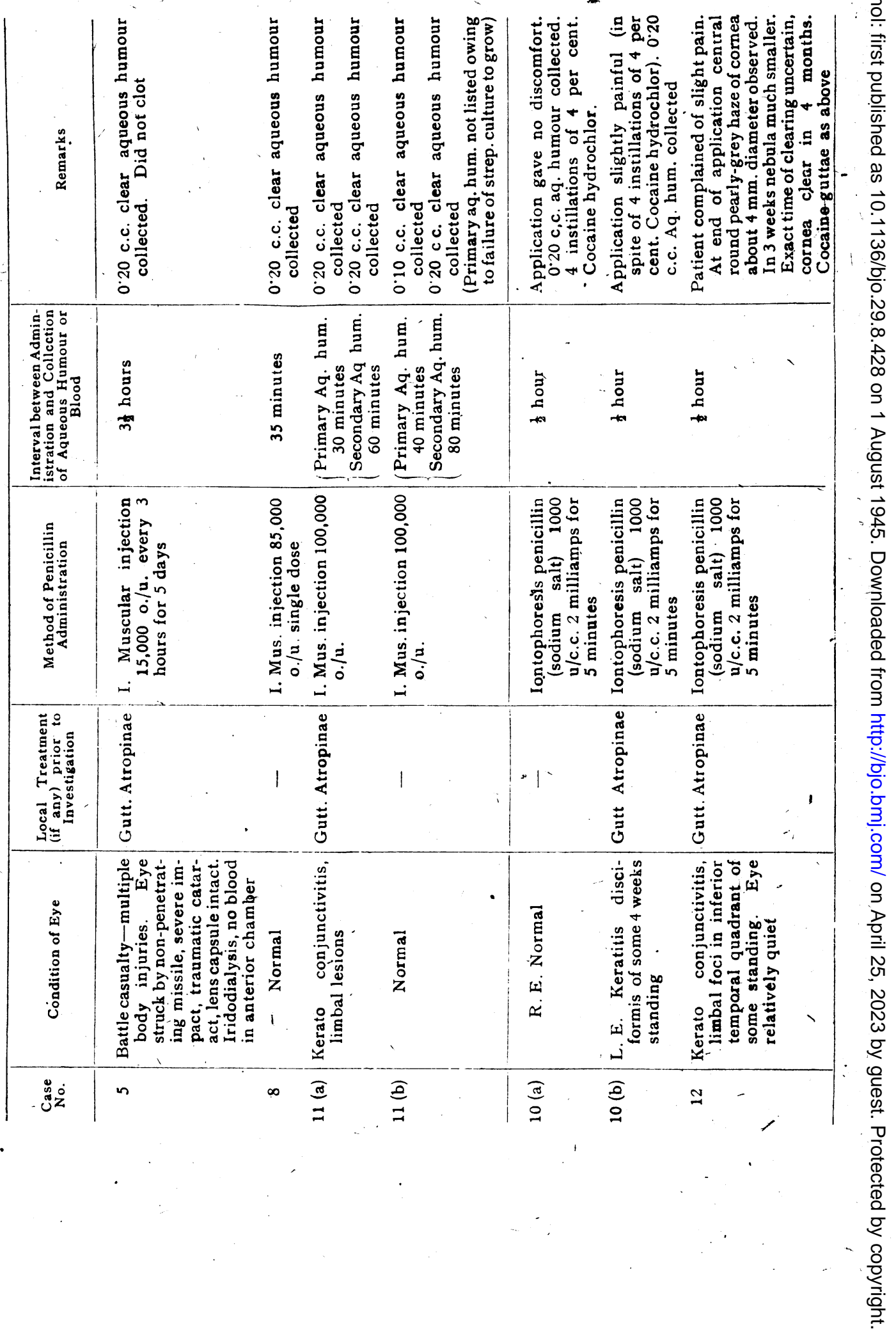


TABLE II

\begin{tabular}{|c|c|c|c|c|c|}
\hline $\begin{array}{c}\text { Case } \\
\text { No. } \\
\vdots\end{array}$ & Treatment & $\begin{array}{c}\text { Highest } \\
\text { concentration } \\
\text { of aqueous } \\
\text { humour } \\
\text { examined }\end{array}$ & $\begin{array}{c}\text { Presence of } \\
\text { Bacteriostasis }\end{array}$ & $\begin{array}{l}\text { Highest } \\
\text { dilution of } \\
\text { fluid with } \\
\text { Bacteriostasis }\end{array}$ & $\begin{array}{l}\text { Estimated } \\
\text { Penicillin } \\
\text { content of } \\
\text { Aqueous } \\
\text { Humour. }\end{array}$ \\
\hline $\begin{array}{r}-2 \\
3\end{array}$ & None & $\begin{array}{l}1: 2 \\
1: 2\end{array}$ & 0 & $\dot{-}$ & $\therefore \quad-$ \\
\hline 4 & Penicillin guttae & $1: 2$ & $\mathrm{O}$ & - & - \\
\hline $\begin{array}{r}9 \\
-\quad \\
\end{array}$ & Penicillin lamellae & $1: 2$ & $\mathrm{O}$ & $1-$ & - \\
\hline $\begin{array}{l}1 \\
6 \\
7\end{array}$ & Penicillin irrigation & $\begin{array}{r}1: 2 \\
1: 4 \\
1: 1 \\
-\end{array}$ & $\begin{array}{l}+ \\
0 \\
+\end{array}$ & ]$^{1: 16}$ & $\begin{array}{l}2 \text { units } \\
1 / 8 \text { unit }\end{array}$ \\
\hline $\begin{array}{r}5 \\
8 \\
11 \text { (a) } \\
11 \text { (b) }\end{array}$ & $\begin{array}{l}\text { Penicillin intramuscularly } \\
\left\{\begin{array}{l}\text { Primary aqueous } \\
\text { Secondary aqueous }\end{array}\right. \\
\text { Secondary aqueous }\end{array}$ & $\begin{array}{l}1: 2 \\
1: 1 \\
1: 1 \\
1: 2 \\
1: 2\end{array}$ & $\begin{array}{l}0 \\
0 \\
+ \\
0 \\
+\end{array}$ & $\frac{-}{1: 1^{*}}$ & 1/16 unit \\
\hline 10 (a) & Penicillin ionisation & $\begin{array}{l:}1: 4 \\
1: 4 \\
1: 2\end{array}$ & $\begin{array}{l}+ \\
+ \\
+\end{array}$ & $\begin{array}{l}1: 8 \\
1: 8 \\
1: 8\end{array}$ & $\begin{array}{l}1 \text { unit } \\
1 \text { unit } \\
1 \text { unit }\end{array}$ \\
\hline
\end{tabular}

* Aqueous examined only by Fleming technique.

in only one of the three eyes treated with irrigation of penicillin solution was a comparable inhibition obtained ( 2 units per c.c.). The other two eyes irrigated with a comparable strength of penicillin and for a like period showed an absence of inhibition -in humour diluted 1:4. Undiluted fluid from one of the latter cases gave inhibition of streptococcal haemolysis and had an estimated content of penicillin of $\frac{1}{8}$ unit.

\section{Discussion}

It is emphasised that these observations are incomplete because work was interrupted by circumstances beyond our control.* We felt, however, that observations on the human aqueous humour were sufficiently interesting to record, particularly as they tended to support the results of Von Sallmann and Meyer (1944) obtained with animals. Our results showed that penicillin was capable of traversing the human cornea when introduced into the conjunctival 
sac by continuous irrigation with a solution. The damaged cornea of one of our patients (case 1) apparently allowed considerable penetration but the normal cornea (case 7) was less perméable. $\mathbf{A}$ damáged epithelium (especially if oedematous throughout as in case1), or a cocainised epithelium probably behave as would epithelium treated with a wetting solution. When penicillin was administered intramuscularly, it appeared in the aqueous humour of both primary and secondary types but in very much lower concentration than that attained in the serum. Higher intra-ocular concentrations than those found after intramuscular penicillin were produced in each eýe subjected to iontophoresis, but the improvised apparatus employed by us produced an undesirable complication (corneal nebula). It is, at present, impossible to define the concentration of penicillin in either blood or tissue fluid necessary for therapeutic. effect. It may be, that the small amounts of penicillin reaching. the aqueous humour after intramuscular penicillin or penicillin baths, will prove to be clinically adequate. The fact that high intra-ocular concentrations can be obtained by the iontophoresis method is, however, in our view significant and probably worthy of further investigation.

\section{Summary}

Observations designed to indicate the most effective method of introducing penicillin into the eye are recorded. Penicillin reaches the aqueous humour after local use in the conjunctival sac or after intramuscular injection but the concentrations attained are variable and often low. By the use of iontophoresis, higher intra-ocular concentration can be obtained but the technique requires considerable care and attention.

Note on the technique of iontophoresis

With regard to the general detail of iontophoresis technique and the various theoretical factors governing its use, reference should be made to $\bar{K}$ arbowski's paper on this subject. 'It is essential to employ the.correct type of iontophoresis apparatus and pay careful attention to the detail of technique in order to avoid complications. The design of the active electrode is most important. Various patterns described in the literature would no doubt serve for penicillin but here we need only refer to one which has been used without complications by Dr. MacMillan in the Physiotherapy Department of the Royal Victoria Hospital, Montreal, the detail of which has been given to us through the courtesy of Captain Duncan and Miss Rose of that Department. It consists of a zinc rod about $2 \frac{1}{2}$ inches long with an expanded base $\frac{1}{4}$ inch or more in diameter. This fits into a slightly tapered glass tube about $2 \frac{3}{4}$ inches long with a lateral opening near its middle and a smooth 
mouth somewhat greater in diameter than the average cornea. The top of the zinc rod and the narrower end of the glass, tube are engaged and held by a metal handle about 2 inches long which can be coupled to the negative pole of the battery. The zinc rod is .held in the glass tube in such a way that its expanded foot is about 1 inch from its wider open end. This end of the tube is packed with absorbent cotton, which contacts the zinc above and projects slightly from the mouth of the tube. The cotton is saturated with penicillin solution $500 \mathrm{u} /$ c.c. (in normal saline), and recharged duriff treatment with fresh solution from a syringe through the lateral opening. With this electrode a current of 2 milliamps is passed for 3 minutes the first day, and thereafter daily for 9 days 2 milliamps for 5 minutes. No speculum is used, the current is let in gradually being controlled (presumably) by transformer and resistance. Pantocaine $\frac{1}{2}$ per cent. is used in preference to cocaine. Provided suitable apparatus and technique are used penicillin may be introduced into the globe (undamaged or unruptured) repeatedly via the cornea by iontophoresis. The method has obvious advantages over the repeated introduction of penicillin by means of a needle and syringe in such cases. To effect penetration to the vitreous, applications longer than 5 minutes are likely to be required, but increase in the time of application increases the risk of corneal damage. Only further experience can determine the maximum time of application at each treatment.

We wish to thank Major General L. T. Poole, C.B., D.S.O., Director of Pathology War Office and Brigadier Sir Stewart Duke-Elder, Consulting Ophthalmic Surgeon to the Army for providing facilities for this work to be carried out and for permitting its publication.

\section{REFERENCES}

Bigger, J. W., Thomas, G. E., and Caldwell, W. G. D. (1944).-Jl. Path. and Bact., Vol. LVI, p. 256.

Fleming, A. (1944).-Lancet, Vol. II, p. 620.

HEATLEY, N. G. (1944).-Biochem. Ji., Vol. XXXVIII, p. 61

KARBOWSKI (1939). -Ophthalmologica, Vol. XCVII, p. 166.

Von Sallmann, L. and MEYeR, K. (1944):-Arch. Ophthal., Vol. XXXI, p. 1.

WRIGHT, R. E. (1944).-Brit. Jl. Ophthal., Vol. XXVIII, p. 574.

$\rightarrow$

\section{ANNOTATION}

\section{- The danger of spot diagnosis}

The importance of never saying anything to a patient, either in the consulting room, out-patient department, or at the bedside, which can even indirectly lead the hearer to infer a very bad prognosis is obvious, but not always sufficiently remembered. People 